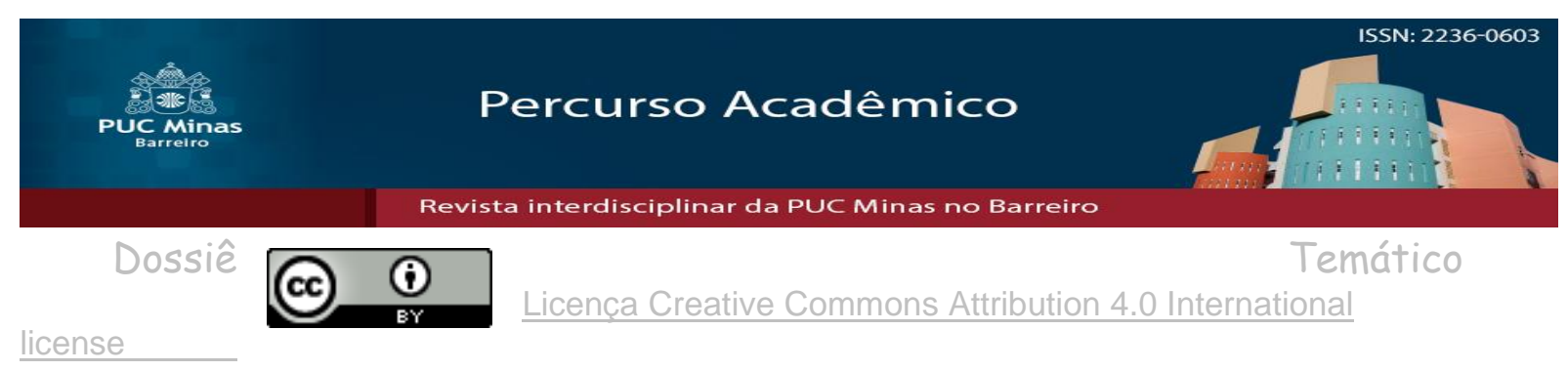

\title{
A aposentadoria na visão dos profissionais do ensino superior
}

Retirement from the perspective of higher education professionals

Ingrid Alves Pereira ${ }^{1}$

Andrea Alcione de Souza ${ }^{2}$

\begin{abstract}
RESUMO
O trabalho muitas vezes ocupa um lugar central na vida dos indivíduos. Isso se torna ainda mais evidente nas profissões que apresentam importante papel social e requerem grande potencial criativo e aptidão, como é o caso dos profissionais docentes. Nesse contexto, o processo de transição para a aposentadoria pode ser bastante desafiador devido ao grande número de mudanças que ocorre na rotina dos trabalhadores e dos estigmas que acompanham a condição de aposentado. Muitos estudos vêm buscando avaliar o impacto da aposentadoria na vida dos indivíduos e alguns fatores que têm sido apontados como mais importantes na vida pós carreira são: os aspectos financeiros, as alterações na rotina, as mudanças no padrão de ocupação do tempo e outros. Para amenizar os efeitos negativos dessa transição, algumas empresas e instituições têm empregado programas de preparo para a aposentadoria (PPAs) a fim de auxiliar seus funcionários a se prepararem para essa fase e sentirem menos os efeitos negativos da vida pós carreira. Nesse sentido, o objetivo deste trabalho foi verificar a visão de professores do ensino superior aposentados sobre a vida pós carreira. Para atender a esse objetivo, foram entrevistados sete professores aposentados de uma instituição privada de ensino superior da cidade de Belo Horizonte, Minas Gerais. Os resultados deste estudo apontaram uma visão bastante variada por parte dos professores entrevistados com relação aos impactos e mudanças trazidos pela aposentadoria. Como aspectos positivos, as respostas evidenciaram uma grande valorização pela maior disponibilidade de tempo para usufruir com a família e lazer na aposentadoria. Em contrapartida um importante aspecto negativo ressaltado pelos entrevistados foi o impacto negativo na vida financeira encontrado na vida pós carreira.
\end{abstract}

Palavras-Chave: Aposentadoria. Professores. Ensino superior. Programas de preparo para a aposentadoria.

\begin{abstract}
The job often occupies a central place in the lives of individuals. This becomes even more evident in professions that play an important social role and require great creative potential and aptitude, as is the case with teaching professionals. In this context, the process of transition to retirement can be quite challenging due to the large number of changes that occur in the routine of workers and the stigmas that accompany the condition of being retired. Many studies have sought to assess the impact of retirement on the lives of individuals and some factors that have been identified as most important in post-career life are: financial aspects, changes in routine, changes in the pattern of time occupation and others. To mitigate the negative effects of this transition, some companies and institutions have used retirement preparation programs (RPPs) to help their employees prepare for this phase and feel less of the negative effects of post-career life. In this sense, the objective of this work was to verify the view of retired higher education teachers on post-career life. To meet this objective, seven retired teachers from a private higher education institution in the city of Belo Horizonte, Minas Gerais, were interviewed. The results of this study showed a very varied view on the part of the teachers interviewed regarding the impacts and changes brought about by retirement. As positive aspects, the responses showed a great appreciation for the greater availability of time to enjoy with family and leisure in retirement. On the other hand, an important negative aspect highlighted by the interviewees was the negative impact on financial life found in post-career life.
\end{abstract}

Artigo recebido em 8 de janeiro de 2021 e aprovado em 10 de novembro de 2021

${ }^{1}$ Graduada em Administração (PUC Minas), Brasil. E-mail: ingrid.alves.3035@gmail.com

${ }^{2}$ Docente de Administração (PUC Minas), Brasil. E-mail: andrea.asouza@uol.com.br 
Keywords: Retirement. Teachers. University education. Retirement preparation programs.

\section{INTRODUÇÃO}

A chegada da aposentadoria traz consigo diversos fatores de mudança na vida dos indivíduos. Enquanto muitos anseiam essa fase, encarando-a como um período de merecido descanso e de liberdade para aproveitar a vida, outros podem apresentar sinais de sofrimento com as grandes mudanças na rotina e a falta da atividade laboral. Os efeitos negativos da aposentadoria podem ser agravados, ainda, devido à associação dessa fase com a chegada da terceira idade. Nesse contexto, os professores do ensino superior representam um grupo de trabalhadores relevante de ser avaliado, visto que muitos optam por continuar lecionando, mesmo na condição de aposentados.

A profissão de docente apresenta um papel social fundamental, além disso, tratase de uma carreira que requer alto nível de aptidão e criatividade, o que faz com que o indivíduo sinta que a sua profissão faz parte de sua identidade, criando um vínculo afetivo com o trabalho. Tais profissionais podem sentir com mais intensidade os efeitos da inatividade durante a aposentadoria.

A situação torna-se ainda mais relevante nos tempos atuais, onde o número aposentados e de idosos no Brasil, assim como em muitos lugares no mundo, vem ficando cada vez maior. Desse modo, torna-se imprescindível, discutir os efeitos que a aposentadoria tem na vida dessa população e de que maneiras as empresas podem contribuir para tornar essa transição mais fácil para os seus funcionários.

Apesar da relevância do tema aposentadoria para a sociedade e para as empresas, ainda são poucos os trabalhos que abordam amplamente todos os aspectos que envolvem essa fase pós carreira, em especial no caso dos professores do ensino superior. Os dados da literatura mostram que são poucas as instituições que investem em programas de preparo para aposentadoria (PPAs), e aquelas que o fazem apresentam desafios e dúvidas de como elaborar e implementar tais programas (BOEHS; SILVA, 2017; SILVA; HELAL, 2019).

Com base na relevância do tema para a sociedade atual, este trabalho tem por objetivo compreender melhor a visão de professores do ensino superior aposentados sobre as mudanças e os impactos em suas vidas da passagem da atividade de docência para a aposentadoria. 
Para atender tal objetivo, foi aplicado um roteiro de entrevista estruturado com perguntas preferencialmente abertas por meio da plataforma digital Google Forms a professores do ensino superior aposentados. A escolha da entrevista como ferramenta de pesquisa se deve principalmente ao fato de se tratar de uma pesquisa qualitativa e também ao fato de esta ser uma ferramenta flexível que possibilita a obtenção dos resultados de forma eficaz e precisa. Além disso, como o objetivo do estudo é obter uma melhor compreensão da visão dos professores sobre a aposentadoria, a entrevista mostra-se uma ferramenta eficaz. A escolha da plataforma Google Forms para veicular as perguntas se deve a sua facilidade e praticidade e principalmente ao cenário de pandemia de COVID19 que acabou por inviabilizar os encontros presenciais durante a ocorrência do estudo. Após a coleta dos dados, as respostas obtidas para cada uma das perguntas foram analisadas e uma súmula dessas respostas foi apresentada nos resultados do presente estudo, destacando as ideias principais dos entrevistados para cada tópico proposto. As respostas foram organizadas seguindo quatro categorias temáticas, a saber: 1) Sobre a vivência profissional em IES; 2) Sobre as atividades atuais; 3) Sobre os fatores de mudança após a aposentadoria e 4) Sobre o processo de desligamento.

Deste modo, acredita-se que este trabalho irá contribuir para uma melhor compreensão dos possíveis temores e expectativas que os profissionais - neste caso professores do ensino superior - possam ter com relação ao processo de aposentar-se. Esta compreensão, por sua vez, pode contribuir, por exemplo, para a elaboração e implementação de PPAs em universidades, de modo a melhorar a vivência e a adaptação a esta importante etapa de transição na vida dos profissionais docentes. O presente estudo pode ainda apontar outras atividades que esses profissionais poderiam desenvolver e assim continuar contribuindo com o desenvolvimento da sociedade.

\section{DESENVOLVIMENTO}

\subsection{Papel do trabalho e da carreira profissional}

O trabalho é alvo de estudos de diversas classes diferentes do conhecimento, como: sociologia, antropologia, economia, filosofia e psicologia e é um tema inerente à história da humanidade (NEVES et al., 2018, p. 319). Desde a Revolução Industrial, no século XIX, o trabalho e a carreira profissional têm ocupado cada vez mais um lugar importante na vida das pessoas (BOEHS et al., 2017). E desde então o conceito e o 
significado do trabalho para a sociedade têm assumido diferentes formas e passado por muitas transformações que acompanham as mudanças do mundo capitalista e cada vez mais globalizado (SCHWEITZER et al., 2016).

$\mathrm{Na}$ visão marxista, o trabalho pode ser definido como "a capacidade de transformar a natureza para atender as necessidades humanas" (MARX, 1993 apud TOLFO; PICCININI, 2007). No entanto, o sentido do trabalho ultrapassa a simples ação, e até mesmo as necessidades financeiras, como fica claro no estudo realizado por Boehs e Silva (2017). Ao entrevistar 13 profissionais aposentados de uma empresa multinacional, os resultados do estudo de Boehs e Silva mostraram que o trabalho e a carreira profissional estão bastante vinculados ao sentimento de utilidade, autoestima, independência financeira e realização pessoal, como é possível observar pelo relato a seguir de um dos entrevistados:

Trabalho, além de ser um meio de sustento necessário para a sobrevivência, é também, acima de tudo, uma forma de a gente vir para esse mundo, tornar-se útil para a sociedade, desempenhar nosso papel de bom cidadão, bom cristão, honesto cidadão e é através do trabalho que a gente vai se dignificar e fazer algo pela sua existência nesse mundo. Sem trabalho ninguém consegue ser alguém na vida. (P11, masculino). (BOEHS; SILVA., 2017, p. 145)

De acordo com Trigueiro apud Boehs e Silva (2017, p.145), atualmente o trabalho tem a capacidade de satisfazer três necessidades importantes para o ser humano: a de subsistência, representada pelo papel financeiro que o trabalho possui; a necessidade de criação, que representa a importância psicológica do trabalho; e, por fim, a necessidade de utilidade, representando o papel social do trabalho.

É importante notar que no caso das profissões com maior apelo criativo, o trabalho pode ter um sentido ainda mais importante e maior apelo emocional, visto que nestes casos o aspecto vocacional é preponderante e, por isso, o profissional acaba apresentando, antes de tudo, um compromisso consigo, e não com uma instituição, como pode ocorrer em outros serviços (BENDASSOLLI; BORGES-ANDRADE, 2011).

\subsubsection{O perfil do profissional docente}

A carreira de professor, assim como outras profissões, surgiu em resposta a uma demanda da sociedade e constituiu-se em torno de uma organização com normas e valores estabelecidos ao longo dos anos e que hoje caracterizam essa profissão (IZA et al., 2014). 
O professor é um profissional que deve estar sempre em construção, ajustando sua didática e seu conhecimento de acordo com o momento e o contexto em que se insere, por isso podemos dizer que se trata de uma profissão que requer muita vocação e dedicação (MACHADO; LUCAS, 2017). O trecho a seguir, relata algumas das características e qualidades exigidas pela profissão:

Podemos dizer que a profissão de docente envolve toda uma identidade profissional que se constrói com anos de trabalho (MACHADO; LUCAS, 2017). Identidade neste contexto pode ser definida como "um processo de construção social de um sujeito historicamente situado". Tratando-se de uma identidade profissional, ela está fortemente relacionada ao significado dessa profissão para a sociedade, bem como de toda a sua trajetória na história da humanidade, suas tradições e contradições (IZA et al., 2014).

A criação da identidade profissional requer muitas processos e aptidões por parte do professor, tais como: domínio cognitivo e instrumental, didática, socialização com os alunos e a própria vivência profissional. Este processo de "tornar-se professor" envolve ainda muitos aspectos de ordem emocional e simbólicos, até o momento que este indivíduo, de fato, assuma a carreira de magistério e a identidade de educador (MACHADO; LUCAS, 2017). A "construção" do docente recebe influência ainda de aspectos como: o modo de relacionamento com os alunos, da disciplina que ensinam, dos papéis que desempenham socialmente, de todo o contexto social e cultural do ensino em que atuam, das condições em que estes profissionais trabalham e de seus aspectos pessoais (como a sua própria biografia, influências, inspirações e etc.). Todos estes aspectos contribuem para a visão que o profissional docente tem de si próprio, dos sentidos que dão ao seu trabalho e da construção de sua identidade profissional diante da sociedade como um todo (FLORES, 2014).

O fato de o docente ter essa identidade profissional e um grande papel para a sociedade reflete a grande responsabilidade do professor com a sua função social, o que faz com que muitos professores tenham grande comprometimento e apego emocional com seu trabalho (IZA et al., 2014).

\subsection{Aposentadoria: aspectos psicossociais}

A aposentadoria é um direito social moderno que começou a se estabelecer no fim do século XIX nos países mais industrializados da época (MACHADO; LUCAS, 2017). 
Este direito surgiu em resposta a uma necessidade da sociedade de garantir o sustento e a manutenção das necessidades básicas dos trabalhadores na velhice (NASCIMENTO; POLIA, 2019; MACHADO; LUCAS, 2017). No Brasil, a história da aposentadoria, passou por diversos processos até que se estabelecesse como direito social, tal como é atualmente. A Constituição de 1988 foi um importante passo neste processo, visto que nela foram definidos muitos parâmetros de cidadania com relação aos idosos (NASCIMENTO; POLIA, 2019).

Nas últimas décadas, o processo de aposentar-se passou por algumas transformações em decorrência das próprias mudanças da sociedade. Por exemplo, no século XIX, quando a aposentadoria começou a ser adotada, a expectativa de vida da população era muito mais baixa que a atual, deste modo o número de aposentados era bem inferior ao que encontramos nos dias de hoje. Da mesma maneira, a compreensão e a vivência da velhice também mudaram, o que trouxe a necessidade de se avaliar a forma como este período é sentido dentro da nossa sociedade contemporânea (FONTOURA; DOLL; OLIVEIRA, 2015).

A questão da aposentadoria é tema de múltiplas áreas de conhecimento, como: psicologia, administração, sociologia, economia e geriatria (BOEHS et al., 2017). O período de aposentar-se representa uma fase de transição importante na vida do indivíduo que pode ser compreendido tanto como uma libertação tanto como um período de crise (MACHADO; LUCAS, 2017).Tomar a decisão de aposentar-se depende de uma série de questões que devem ser levadas em consideração, como por exemplo: o tipo de relação que o indivíduo tem com o trabalho, a organização prática das atividades diárias, o contexto social e demográfico no qual o profissional se insere e também as questões do contexto familiar (ANTUNES; MORÉ, 2014).

As mudanças vivenciadas durante a aposentadoria são muitas. Neste processo, o indivíduo tem que lidar com o estigma social de que o aposentado é inativo e "não precisa fazer nada". O indivíduo aposentado pode enfrentar conflitos com relação a sua capacidade de trabalhar e produzir, começa a desempenhar por mais tempo os papéis como o de pai/mãe e avô/avó, o que antes não acontecia devido às suas obrigações profissionais (MACHADO; LUCAS, 2017). Devido ao impacto dessas transformações, torna-se fundamental pensar em maneiras de como o lugar do trabalho pode ser preenchido no processo de transição para a aposentadoria. O cenário é ainda mais relevante se levarmos em conta o número significativo de idosos no Brasil, que deve 
alcançar a marca de 32 milhões no ano de 2020, segundo dados do IBGE (NASCIMENTO; POLIA, 2019; IBGE, 2017).

O processo de envelhecimento normalmente coincide com o período de aposentadoria, o que por si só já traz transformações desafiadoras para o indivíduo, visto que se trata de uma fase de perdas e ganhos (CANIZARES; JACOB FILHO, 2011; NASCIMENTO; POLIA, 2019). No entanto, alguns estudos mostram que pessoas que se aposentam em idade menor têm maior dificuldade na adaptação à aposentadoria (BOEHS; SILVA, 2017). Outra questão que influencia na transição para a vida póscarreira é o impacto financeiro que normalmente ocorre neste processo. Muitos profissionais, ao se aproximarem da aposentadoria, ficam ansiosos devido à redução da renda neste período, o que pode ser ainda pior se o indivíduo ainda tiver filhos financeiramente dependentes (CANIZARES; JACOB FILHO, 2011). É sabido que pessoas com maior poder aquisitivo têm melhores chances de se adaptar a essa fase (BOEHS; SILVA, 2017).

Canizares e Jacob Filho (2011) observaram que os indivíduos que possuem maior nível de autoridade no trabalho e maiores níveis de escolaridade apresentam melhores condições de se adaptar à aposentadoria por conseguirem administrar melhor o tempo livre. Os resultados deste estudo mostram que quanto maior a autoridade do indivíduo em sua profissão, melhores são as condições de suporte emocional e menores são os níveis de ansiedade e preocupação neste processo de transição.

De acordo com os resultados descritos por Boehs e Silva (2017), o planejamento da aposentadoria se mostrou um fator positivo à adaptação a esta fase, neste sentido, os indivíduos que buscam outras atividades na vida pós carreira, como trabalhos voluntários, estudo e lazer, sofrem menos com essa transição. Os estudos relatados por Boehs e Silva, também mostram que pessoas que se aposentam involuntariamente e abruptamente têm maior dificuldade em se adaptar à inatividade.

A aposentadoria também se mostrou um importante fator de risco para a senilidade. Neste sentido, Canizares e Jacob Filho (2011) alertam para a importância de se considerar o processo de aposentadoria como um possível fator de risco à saúde. Os resultados relatados pelos autores indicam que a aposentadoria está relacionada ao envelhecimento patológico e instabilidade emocional, podendo ter consequências nocivas para os indivíduos. 


\section{RESULTADOS E DISCUSSÃO}

\subsection{Perfil dos entrevistados}

O presente trabalho contou com a participação de sete professores aposentados do ensino superior, dentre os quais cinco eram mulheres e apenas dois eram homens. Quanto à faixa etária dos entrevistados, cinco participantes apresentavam idades entre 60 e 70 anos, um participante apresentava-se na faixa etária de 50 a 60 anos e um participante se apresentava com idade superior a 70 anos. Quanto ao estado civil, seis participantes eram casados e apenas um participante era divorciado.

Dentre os professores entrevistados, quatro responderam ter atuado por mais de 30 anos como professores no ensino superior. Os três restantes declararam ter atuado entre 25 e 30 anos como docentes do ensino superior.

Quanto ao perfil de formação acadêmica, cinco professores apresentavam como maior nível de formação o doutorado, enquanto dois professores apresentavam o mestrado como maior nível de formação.

A fim de preservar o anonimato dos entrevistados, os professores participantes dessa pesquisa serão identificados da seguinte forma:

- Professora 1: sexo feminino, casada, apresentava-se na faixa etária de 60 a 70 anos de idade no momento da entrevista, declarou ter atuado como docente no ensino superior por um período entre 25 e 30 anos e possui o doutorado como maior nível de formação.

- Professora 2: sexo feminino, casada, apresentava-se na faixa etária de 60 a 70 anos de idade no momento da entrevista, declarou ter atuado como docente no ensino superior por um período entre 25 e 30 anos e possui o doutorado como maior nível de formação.

- Professor 3: sexo masculino, casado, apresentava-se na faixa etária de 60 a 70 anos de idade no momento da entrevista, declarou ter atuado como docente no ensino superior por um período de mais de 30 anos e possui o mestrado como maior nível de formação.

- Professor 4: sexo masculino, casado, apresentava-se na faixa etária de mais de 70 anos de idade no momento da entrevista, declarou ter atuado como docente no ensino 
superior por um período de mais de 30 anos e possui o mestrado como maior nível de formação.

- Professora 5: sexo feminino, divorciada, apresentava-se na faixa etária de 50 a 60 anos de idade no momento da entrevista, declarou ter atuado como docente no ensino superior por um período entre 25 e 30 anos e possui o doutorado como maior nível de formação.

- Professora 6: sexo feminino, casada, apresentava-se na faixa etária de 60 a 70 anos de idade no momento da entrevista, declarou ter atuado como docente no ensino superior por um período de mais de 30 anos e possui o doutorado como maior nível de formação.

- Professora 7: sexo feminino, casada, apresentava-se na faixa etária de 60 a 70 anos de idade no momento da entrevista, declarou ter atuado como docente no ensino superior por um período de mais de 30 anos e possui o doutorado como maior nível de formação.

Para fins didáticos, as perguntas da entrevista foram divididas em categorias temáticas, sendo elas: 1) Sobre a vivência profissional em IES; 2) Sobre as atividades atuais; 3) Sobre os fatores de mudança após a aposentadoria e 4) Sobre o processo de desligamento. A seguir, os dados coletados serão apresentados seguindo essas categorias temáticas.

\subsection{Sobre a vivência profissional em instituições do ensino superior}

Sobre o regime de trabalho na época próxima ao desligamento das atividades profissionais, três professores responderam que trabalhavam em regime de dedicação parcial, dois professores responderam trabalhar em regime de dedicação integral e outros dois responderam atuar como professor aulista. Já quanto à carga horária de trabalho próximo ao período de desligamento profissional, quatro professores responderam trabalhar de 30 a 40 horas semanais, dois professores responderam trabalhar de 20 a 30 horas semanais e um professor respondeu trabalhar até 10 horas semanais. Segundo Krawulski et al. (2017), um fator importante nos programas de preparo para a aposentadoria seria a redução gradual da jornada de trabalho e das exigências na produção no período de transição. Esse desligamento gradual traria uma adaptação mais fácil para os profissionais. 
Quando questionados sobre como eram as condições de trabalho como docente, as respostas apresentaram-se bastante variadas. Três professores mostraram-se satisfeitos com as condições de trabalho, como o Professor 3 que respondeu: "Ótimas condições na maioria dos aspectos", ou a Professora 1 que se limitou a dizer: "Excelente". Já outros dois entrevistados mostraram-se bastante insatisfeitos com as condições de trabalho: a Professora 5 declarou o seguinte: "Absurdamente cobrada e trabalho sem descanso. Altamente explorada!" e a Professora 7 que respondeu que as condições eram "Relativamente precárias, por excesso de aulas repetitivas para graduação e sem tempo específico para pesquisas".

Nessa mesma linha de raciocínio, uma outra pergunta realizada dentro dessa categoria foi se os entrevistados se consideravam satisfeitos e realizados com seu trabalho como docente nos anos próximos ao seu desligamento. Em concordância com as respostas à questão anterior, o nível de satisfação também se mostrou bastante variado, com alguns professores declarando estar mais satisfeitos e outros demonstrando maior insatisfação. Essa diversidade no perfil das respostas parece refletir a ambiguidade que existe na carreira do profissional docente. Se por um lado o professor tem, muitas vezes, um forte vínculo afetivo pela profissão e vê em sua carreira uma realização pessoal (MACHADO; LUCAS, 2017), por outro aspecto, o docente do ensino superior é fortemente cobrado, possuindo muitas vezes tarefas múltiplas que se estendem além da sala de aula, que incluem serviços administrativos, orientação de trabalhos, pesquisas e publicação de artigos (KRAWULSKI et al., 2017). Essa sobrecarga pode gerar grande estresse e, por vezes, insatisfação nos profissionais da área. De acordo com as respostas obtidas na entrevista, foi possível observar também que o nível de satisfação profissional depende de algumas variáveis importantes, como, por exemplo: fase pessoal, gerência, relacionamentos profissionais e instituição de ensino em que atuaram.

Com relação aos vínculos e relacionamentos no trabalho, todos os professores entrevistados responderam ainda manter alguns vínculos de amizade ou profissionais com alguns colegas de trabalho.

\subsection{Sobre as atividades atuais}

Quando questionados sobre suas atividades atuais, todos os professores entrevistados declararam estar praticando algum tipo de atividade. Dentre eles, quatro 
professores responderam fazer algum trabalho voluntário. O professor 3 declarou ter entrado em uma sociedade de uma pequena empresa, a professora 7 respondeu ser aprendiz de bordadeira e produtora rural e a professora 6 foi a única a ter declarado continuar com atividades relacionadas à educação e pesquisa: "Continuo escrevendo $e$ publicando artigos, além de participar de um grupo de estudos temático". Com relação aos motivos que levaram os professores aposentados a permanecerem com algum nível de atividade, duas respostas se destacaram: o professor 3 declarou o seguinte: "Porque me considero ainda em ótima fase para o trabalho e com muito potencial produtivo”. Já a professora 7 mostrou preocupação também com o lado financeiro, respondendo continuar atuando "para compor a renda e fazer a diferença na vida". De acordo com Krawulski et al. (2017), a permanência em atividades profissionais na aposentadoria de professores universitários, está fortemente relacionada ao sentimento de reconhecimento proporcionado pelas atividades e pela preservação do intelecto ativo. Embora no presente estudo apenas a professora 6 tenha declarado ter mantido atividades relacionadas à docência, observou-se que todos os entrevistados buscaram algum tipo de atividade na vida pós carreira, com uma porcentagem elevada buscando o trabalho voluntário, o que reforça a hipótese de que o motivo das atividades vai além do aspecto financeiro.

Quando foram questionados se em suas atividades atuais mantinham os relacionamentos da época de atuação na docência, a maioria dos professores (5/7) declarou manter parcialmente alguns de seus contatos nas suas atividades na vida pós carreira.

\subsection{Sobre os fatores de mudança após a aposentadoria}

Nessa categoria, a primeira questão refere-se ao impacto financeiro da aposentadoria. Quando foram questionados sobre isso, todos os professores responderam que após a aposentadoria sua renda mensal diminuiu. De fato, a redução na renda mensal tem se mostrado um dos principais fatores de mudança na vida pós carreira. Segundo Canizares e Jacob Filho (2011), o impacto na vida financeira é um dos principais motivos de apreensão e ansiedade dos profissionais na proximidade com a aposentadoria. Ainda, segundo os autores, para grande parte dos trabalhadores, o fim das atividades profissionais traz uma redução significativa na renda, o que pode levar a uma desestabilização econômica e mudanças nos padrões de vida do aposentado. Esse impacto financeiro, associado a outras mudanças na rotina, seriam fatores predisponentes ao 
envelhecimento patológico (CANIZARES; JACOB FILHO, 2011). Em contrapartida, observa-se que, embora a questão econômica seja um fator preocupante, de acordo com Krawulski et al. (2017), quando se avaliam os professores que optaram por permanecer com as atividades de docente mesmo após a aposentadoria, o aspecto financeiro não se mostra o principal motivo para a manutenção das atividades profissionais, visto que muitos atuam de forma voluntária. Nesses casos, o vínculo afetivo com o trabalho seria o motivo predominante.

Com relação à forma como ocupam seu tempo livre na aposentadoria, a maior parte dos professores (6/7) respondeu ocupar o tempo com a família. As outras atividades que mais apareceram foram: cursos (3), exercício físico (3), viagens e meditação (com 2 cada).

Quando questionados sobre os impactos da aposentadoria com relação a: tempo com a família e amigos, lazer e cuidados pessoais, a maior parte das respostas se mostram positivas, como a professora 1 que respondeu: "tudo ficou mais fácil", e a professora 5 que declarou: "Estou amando poder gerir o meu tempo!!!!". No entanto, alguns professores lamentaram o fim das atividades, como a professora 6, que declarou:

O principal impacto para mim foi ficar sem a sala de aula, em que eu desenvolvia um trabalho que me gratificava muito no contato com os alunos. O segundo foi perder o local que eu frequentei cotidianamente durante 40 anos como aluna e professora. Mantenho os cuidados pessoais, mas os demais aspectos foram comprometidos pelo isolamento decretado pela pandemia. (Professora 6)

Essa declaração da entrevistada levanta uma outra questão importante a ser mencionada, que é a situação atípica vivenciada no momento da realização desse estudo causada pela pandemia da COVID-19. Os impactos do isolamento social também podem ter causado alterações na percepção e vivência dos entrevistados, principalmente daqueles que se aposentaram mais recentemente.

Com relação à qualidade de vida na aposentadoria, a maior parte dos professores (4 /7) declarou que houve uma melhora significativa. Um professor optou por não responder e dois professores mostram algum nível de insatisfação com o fim das atividades profissionais, como a professora 6 :

Penso que piorou bastante, por não estar atuando diretamente e pela queda salarial. O contraponto foi desenvolver uma compreensão maior da situação e abrir o meu leque de conhecimentos, possibilitados pelo ganho do tempo antes tomado pelas exigências profissionais. (Professora 6). 
Ainda com relação à qualidade de vida e satisfação na vida pós carreira, Panozzo e Monteiro (2013) enfatizam que a aposentadoria fornece ao indivíduo a possibilidade de viver em um mundo de não trabalho e isso pode ser percebido de forma positiva ou negativa por ele, como os autores detalham a seguir:

\begin{abstract}
Muitas pessoas podem sentir esse momento [a aposentadoria] de maneira dolorosa, permeado de sentimentos de insegurança e dúvidas em relação ao vazio provocado pela falta da atividade, do trabalho, bem como pela perda dos vínculos oriundos do ambiente laboral. De um lado, o rompimento do ciclo da produtividade com o trabalho, a tomada de consciência de não pertencer mais àquele grupo profissional e a associação dessa fase ao envelhecimento caracterizam aspectos ambíguos nessa transição da aposentadoria. Por outro lado, de forma positiva, apresentam-se o direito ao descanso, ao usufruto do tempo livre, à escolha sobre o quê, onde e de que forma realizar as atividades com a família e os amigos. Descobrir novos interesses, imprimir outro ritmo na maneira de viver, primando pela qualidade de vida, sem os compromissos, as regras e as rotinas tão peculiares ao trabalho, são escolhas possíveis a partir de então (PANOZZO; MONTEIRO, 2013, p. 200).
\end{abstract}

Essa visão dos autores, mostra-se em concordância com o perfil das respostas obtidas na entrevista, em que alguns professores demonstraram satisfação e melhora na qualidade de vida associados à maior disponibilidade de tempo e liberdade, enquanto outros mostraram-se perdidos e ansiosos com a mudança na rotina. Ainda a este respeito, Machado e Lucas (2017) enfatizam ainda que a maneira como cada indivíduo sente e vive a aposentadoria depende de fatores pessoais, como a sua história de vida, suas relações, seu nível de vínculo com o trabalho e também à forma como cada indivíduo lida com as perdas e mudanças da vida.

Quando foram questionados sobre quais aspectos mudaram na saúde física e mental após a aposentadoria, três dos sete professores entrevistados responderam ter ficado menos estressados e três responderam também ter ficado menos ansiosos. Os professores 1, 2, 3 e 5 também salientaram que na aposentadoria tiveram mais tempo para levar uma vida mais saudável, com melhorias na alimentação e na frequência de atividades físicas. Em contraponto, a professora 6 declarou ter tido dificuldades de lidar com a falta da a atividade profissional, mostrando-se mais ansiosa, evidenciando assim um outro aspecto da vida pós carreira.

Sobre os impactos da aposentadoria na saúde física e mental, Panozzo e Monteiro (2013) relatam que a relação entre a saúde e a aposentadoria dependem de três fatores principais: a idade na qual o indivíduo se aposentou, o motivo da aposentadoria e o tempo que o indivíduo tem de aposentado. Ainda, segundo os autores, os casos de aposentadoria voluntária mostram melhores resultados para a saúde, mas essa melhora parece ser 
atenuada com o passar dos anos. Percebe-se também que a saúde mental está diretamente associada com o tema da satisfação e qualidade de vida tratados anteriormente, desse modo, espera-se que os indivíduos que percebem a aposentadoria de forma negativa, apresentem maiores problemas nessa fase, como ansiedade e depressão, enquanto aqueles que percebiam o trabalho como um fator estressante apresentem melhorias nesses aspectos.

\subsection{Sobre o processo de desligamento}

Nesta categoria foram abordados pontos relativos ao processo de desligamento das atividades profissionais. Quando foram questionados se o processo de desligamento envolveu todos os ritos (legais e profissionais) de forma adequada, três professores responderam que sim, dois professores responderam que não e dois professores optaram por não responder à pergunta.

Com relação a eventos de despedida, quatro professores responderam não ter tido qualquer tipo de evento no processo de desligamento de suas atividades profissionais e três professores responderam ter tido apenas um encontro informal com os amigos. Tais eventos mostram-se importantes no processo de desligamento do profissional, que se sente querido e valorizado pelos anos de dever cumprido. Segundo Machado (2016), os ritos de passagem marcam transições importantes na vida dos indivíduos, sejam eles eventos festivos formais ou não, transmitindo uma sensação de segurança e de coesão social. $\mathrm{O}$ fato de a maior parte dos professores entrevistados ter declarado não ter tido qualquer tipo de evento de despedida - e aqueles que tiveram terem sido apenas eventos informais com amigos - evidencia a falta de preparo das instituições e empresas para lidar e auxiliar os funcionários que estão enfrentando o processo de transição para a aposentadoria.

Quando questionados se achariam bom que as IES elaborassem algum plano de desligamento voluntário, a maior parte dos entrevistados respondeu achar que seria algo positivo, como o professor 4, que declarou: "Sim. facilitaria a tomada de decisão do docente". De acordo com Melo (2017), a aposentadoria compulsória ocorre de modo automático, tendo vigência a partir do dia exato em que o trabalhador atingir a idade limite. Já na aposentadoria voluntária, o servidor que cumpriu os requisitos legais tem a oportunidade de manifestar a sua vontade, desse modo, a principal diferença seria o 
respeito à escolha do trabalhador, que teria a possibilidade de refletir e ponderar a sua decisão. Segundo França et al. (2013), a decisão de se aposentar pode estar vinculada a fatores como idade, saúde, relacionamentos familiares, status financeiro e vínculo com o trabalho.

Em seguida, os professores foram questionados se acreditavam que as IES deveriam adotar um programa de preparação para a aposentadoria. Dentre os sete entrevistados, cinco professores responderam que seria bom ter um programa de preparo, como a professora 6 , que declarou:

Esse programa seria o ideal em vários aspectos. Muitas empresas adotam com sucesso. Ainda mais em uma instituição declaradamente confessional, seria de se esperar essa preocupação. O que requer um setor de recursos verdadeiramente humanos e atuante. (Professora 6)

Ainda nessa questão, o professor 3 comentou o seguinte:

Sim, com certa antecedência de modo que os professores pudessem se preparar [...]. Este programa poderia, por exemplo, estar ligado a diversas questões como idade, atividades, etc.... e permitiria, também, um programa de preparação por parte do professor. (Professor 3)

Os programas de preparo para aposentadoria (PPAs) constituem um conjunto de ações propostas pela empresa a fim de auxiliar os profissionais a se prepararem para a vida pós carreira (PAZZIM; PUGA, 2016). Muitas empresas têm implementado PPAs com sucesso nos últimos anos (MURTA et al., 2014; OLIVEIRA; SILVA, 2018; MARANGONI et al., 2017). Sobre a importância e o papel desses programas no mundo atual, Nascimento (2018, p. 63) argumenta:

É perceptível o quanto a preocupação com o bem-estar físico e mental se tornou importante para todos principalmente para aqueles que estão adentrado nessa fase da aposentadoria. Por isso é essencial que se tenha um certo planejamento para vivenciar essa fase de forma tranquila. O PPA vai ajudar nesse planejamento para que o pré aposentado não sofra com os diversos males ocasionados com a chegada desse momento. Estar com a mente tranquila para encarar essa fase é essencial como também manter boas relações com os familiares e amigos, pois eles serão os que darão o apoio necessário nessa hora (NASCIMENTO, 2018, p. 63).

Embora os PPAs tenham se mostrado eficazes e sejam considerados importantes tanto pelos funcionários como pelos próprios empreendedores, ainda são poucas as instituições que adotam esse tipo de programa. Segundo um levantamento feito por França et al. (2014), apenas 23\% dos gestores apresentam PPAs em suas instituições, embora $82,5 \%$ deles considere que estes programas se classifiquem como importantes ou muito importantes. Com base nos relatos da literatura, percebe-se que os PPAs seriam uma importante ferramenta de gestão para auxiliar os professores e demais profissionais 
que estão passando por essa fase de transição, uma vez que as mudanças são muitas e que nem todos vivenciam este momento de forma positiva.

\section{CONSIDERAÇÕES FINAIS}

A partir dos resultados obtidos no presente estudo, foi possível perceber que a vivência da aposentadoria pelos professores universitários entrevistados mostrou-se variada, embora em grande parte os professores tenham ressaltado os aspectos positivos da mesma. Percebe-se que existem diversas variáveis que interferem na forma como essa fase é percebida pelos professores, tais como aspectos financeiros, percepção do trabalho, idade, fase da vida e características pessoais. Com relação aos impactos e mudanças trazidas pela aposentadoria, de acordo com a resposta dos entrevistados, destacou-se a valorização pela maior disponibilidade de tempo para usufruir com a família e lazer. Em contrapartida, o impacto negativo financeiro também foi algo relatado pelos professores avaliados.

Outro aspecto que ficou evidente com a análise dos resultados foi a aparente dualidade que existe com relação à satisfação com a profissão de docente do ensino superior que parece ser inerente à profissão. Por um lado, a profissão de professor tem grande papel social, fazendo com que os indivíduos que atuem nessa área se identifiquem com esse papel e tenham grande apelo emocional pela profissão, em oposição, os docentes frequentemente são profissionais com alta carga de trabalho e tarefas múltiplas que vão além da sala de aula, essa sobrecarga parece ter um efeito negativo na percepção dos professores que acabam apresentando sinais como estresse e ansiedade, causados pela profissão. Esse nível de satisfação com o trabalho durante o período de atuação próximo à aposentadoria parece ser fundamental também na forma como os profissionais sentem a aposentadoria. No presente estudo, foi possível observar que os professores insatisfeitos com a atividade profissional perceberam a aposentadoria como algo mais positivo, enquanto aqueles que se apresentavam mais satisfeitos e envolvidos com a profissão mostram sentir falta das atividades laborais, apresentando até mesmo sinais como aumento da ansiedade e estresse com o advento da aposentadoria.

Outro aspecto relevante a se argumentar é que o presente estudo foi realizado durante o período de pandemia da COVID-19 e que, por isso, a rotina dos entrevistados pode ter sofrido alterações causadas pelas mudanças de isolamento social impostas nessa 
fase, o que também pode ter influenciado na percepção dos professores entrevistados, principalmente quanto à saúde mental, como foi relatado no depoimento da professora 6 .

Por fim, conclui-se que a aposentadoria trouxe grandes mudanças na rotina e qualidade de vida dos professores, sejam essas mudanças positivas ou não. No presente estudo, a maior parte dos professores entrevistados mostrou-se satisfeita com a aposentadoria. No entanto, alguns também mostraram certa dificuldade de adaptação a essa fase. Desse modo, verifica-se a necessidade de que os profissionais sejam mais bem preparados para a chegada dessa etapa nos anos que antecedem a transição para a inatividade. Uma forma que parece ser eficaz de lidar com essa questão é a implementação de PPAs por parte das instituições. A possibilidade de implementar um PPA foi percebida de forma positiva pela maior parte dos professores entrevistados. Esses programas seriam não só uma forma de auxiliar e preparar os profissionais para as mudanças trazidas pela vida pós carreira, como também uma forma de valorização e preocupação das empresas e instituições para com seus funcionários.

\section{REFERÊNCIAS}

ANTUNES, Marcos Henrique; MORÉ, Carmen Leontina Ojeda Ocampo. Família, trabalho e aposentadoria: uma revisão da produção científica no cenário brasileiro. Contextos Clínicos, v. 7, n. 2, 2014. Disponível em: < http://pepsic.bvsalud.org/pdf/cclin/v7n2/v7n2a04.pdf > Acesso em: 20 jul. 2020.

BENDASSOLLI, Pedro F.; BORGES-ANDRADE, Jairo Eduardo. Significado do trabalho nas indústrias criativas. RAE, São Paulo, v. 51, n. 2, 2011. Disponível em: < https://www.scielo.br/pdf/rae/v51n2/v51n2a03.pdf > Acesso em: 03 set. 2020.

BOEHS, Samantha de Toledo Martins; SILVA, Narbal. Papel de trabalho, carreira, satisfação de vida e ajuste na aposentadoria. Revista Brasileira de Orientação Profissional, Florianópolis, v. 18, n. 2, dez. 2017. Disponível em: < http://pepsic.bvsalud.org/pdf/rbop/v18n2/03.pdf > Acesso em: 17 jun. 2020.

BOEHS, Samantha de Toledo Martins et al. Revisão da literatura latino-americana sobre aposentadoria e trabalho: perspectivas psicológicas. Revista Psicologia: Ações e Trabalho, Brasília, v. 17, n. 1, p. 54-61, mar. 2017. Disponível em: < http://pepsic.bvsalud.org/pdf/rpot/v17n1/v17n1a07.pdf > Acesso em: 30 out. 2020.

CANIZARES, Juan Carlos Lara; JACOB FILHO, Wilson. Fatores de risco à senilidade na transição à aposentadoria. Revista Brasileira de Geriatria e Gerontologia, Rio de Janeiro, v. 14, n. 3, 2011. Disponível em: < https://www.scielo.br/pdf/rbgg/v14n3/v14n3a03.pdf > Acesso em: 15 maio de 2020. 
FLORES, Maria Assunção. Discursos do profissionalismo docente paradoxos e alternativas conceptuais. Revista Brasileira de Educação, Rio de Janeiro, v. 19, n. 59, dez. 2014. Disponível em: < https://www.scielo.br/pdf/rbedu/v19n59/03.pdf > Acesso: 15 jul. 2020.

FONTOURA, Daniele dos Santos; DOLL, Johannes; OLIVEIRA, Saulo Neves de. O Desafio de Aposentar-se no Mundo Contemporâneo. Educação \& Realidade, Porto Alegre, v. 40, n. 1, mar. 2015. Disponível em: < https://www.scielo.br/pdf/edreal/v40n1/2175-6236-edreal-40-01-00053.pdf $>$ Acesso em: 26 de set. 2020.

FRANÇA, Lúcia Helena de Freitas Pinho et al. Aposentar-se ou continuar trabalhando? O que influencia essa decisão? Psicologia: Ciência e Profissão, Brasília, n. 33, v. 3, ago. 2013. Disponível em: 〈 https://www.scielo.br/pdf/pcp/v33n3/v33n3a04.pdf > Acesso em: 03 out. 2020.

FRANÇA, Lúcia Helena de Freitas Pinho et al. A percepção dos gestores brasileiros sobre programas de preparação para a aposentadoria. Estudo Interdisciplinar e envelhecimento, Porto Alegre, v. 19, n.3, 2014. Disponível em: < https://seer.ufrgs.br/RevEnvelhecer/article/view/50434/33292 > Acesso em: 17 out. 2020.

INSTITUTO BRASILEIRO DE GEOGRAFIA E ESTATÍSTICA - IBGE. Em 2015, esperança de vida ao nascer era de 75,5 anos. Rio de Janeiro: IBGE, 2017.

Disponível em: <https://agenciadenoticias.ibge.gov.br/agencia-noticias/2013-agenciade-noticias/releases/9490-em-2015-esperanca-de-vida ao-nascer-era-de-75-5anos.html >. Acesso em: 02 mai. 2020.

IZA, Dijnanne Fernanda Vedovatto et al. Identidade docente: As várias faces da constituição do ser professor. Revista Eletrônica de Educação, v. 8, n. 2, 2014. Disponível em < http://www.reveduc.ufscar.br/index.php/reveduc/article/viewFile/978/339 > Acesso em 04 jun. 2020.

KRAWULSKI, Edite et al. Docência voluntária na aposentadoria: transição entre o trabalho e o não trabalho. Revista Psicologia: Teoria e Prática, v.19, n. 1, 2017. Disponível em: < http://pepsic.bvsalud.org/pdf/ptp/v19n1/v19n1a04.pdf > Acesso em: 26 jun. 2020.

MACHADO, Cristiane Nervis Conrado; LUCAS, Michele Gaboardi. Aposentadoria: como os professores vivenciam este momento? Revista de Carreiras e Pessoas, São Paulo, v. 7, n. 2, 2017. Disponível em: <

https://revistas.pucsp.br/index.php/ReCaPe/article/view/32753/22619 > Acesso em: 28 maio de 2020.

MACHADO, Sandra. A importância dos ritos de passagem. MultiRio: a mídia educativa da cidade, Rio de Janeiro, 11 de jan. 2016. Disponível em: < http://multirio.rio.rj.gov.br/index.php/leia/reportagens-artigos/reportagens/8585-a impo rtancia-dos-ritos-depassagem\#: :text=As\%20mudan\%C3\%A7as\%20mais\%20signifi cativas $\% 20$ pelas, $\%$ 20casamento $\% 20 \mathrm{e} \% 20 \mathrm{a} \% 20$ morte.\&text=Em\%20Os\%20Ritos $\% 20$ 
Profanos $\% 2 \mathrm{C} \% 20$ Claude, vezes $\% 20$ n $\%$ C $3 \%$ A3o $\% 20$ nos $\% 20$ damos $\% 20$ conta. > Acesso em: 17 nov. 2020.

MARANGONI, Jacqueline Ferraz da Costa et al. Programa de Orientação para Aposentadoria do Governo do Distrito Federal como Estratégia de Prevenção e Promoção da Saúde do Servidor: Relato de Experiência. In: CONGRESSO CONSẢDE DE GESTÃO PÚBLICA, 10., 2017. Brasília: SRTVS, 2017. p. 1-16. Disponível em: < http://consad.org.br/wp-content/uploads/ 2017/05/Painel-07_01.pdf > Acesso em: 19 nov. 2020.

MELO, Ângelo Braga Netto Rodrigues de. Aposentadoria voluntária vs aposentadoria compulsória: o papel da vontade na aposentadoria voluntária e a boa fé objetiva.

Olhares Plurais - Revista Eletrônica Multidisciplinar, n. 16, v. 1, 2017. Disponível em: < http://revista.seune.edu.br/index.php/op/article/view/275/209 > Acesso em: 04 nov. 2020.

MURTA, S.G. et al. Preparação para a Aposentadoria: Implantação e Avaliação do Programa Viva Mais! Psicologia: Reflexão e Crítica, v. 27, n.1, p 1-9, 2014. Disponível em: <http://www.scielo.br/scielo.php?script=sci_arttext\&pid=S0102$79722014000100001 \& \operatorname{lng}=e n \& n r m=i s o>$. Acesso em: 02 nov. 2020.

NASCIMENTO, Daiane Eduardo. Programa de preparação para aposentadoria uma análise da demanda na percepção dos professores do município de soledade PB. Relatório de Estágio Supervisionado (Bacharel em Administração) - Universidade Federal de Campina Grande, 2018.

NASCIMENTO, Pamela Daniel Machado; POLIA, Andreza Aparecida. Planos para o futuro: uma análise da perspectiva ocupacional de professores universitários para o período da aposentadoria. Caderno Brasileiro de Terapia Ocupacional, São Carlos, v. 27, n. 2, 2019. Disponível em: < https://www.scielo.br/pdf/cadbto/v27n2/2526-8910cadbto-2526-8910ctoAO1647.pdf > Acesso em: 13 ago. 2020.

NEVES, Diana Rebello et al. Sentido e significado do trabalho: uma análise dos artigos publicados em periódicos associados à Scientific Periodicals Electronic Library. Cad. EBAPE. BR, Rio de Janeiro, v. 16, n. 2, jun. 2018. Disponível em: < https://www.scielo.br/pdf/cebape/v16n2/1679-3951-cebape-16-02-318.pdf $>$ Acesso em: 28 maio 2020.

OLIVEIRA, Cassio Santana de; SILVA, Jarcilene Martins Souza da. Programa de Preparação Para Aposentadoria - PPA Vida Ativa. DêCiência em Foco, v. 2, n. 1, 2018. Disponível em: < http://revistas.uninorteac.com.br/index.php/DeCienciaemFoco0/article/view/155/52 > Acesso em: 11 nov. 2020.

PANOZZO, E.A.L.; MONTEIRO, J.K. Aposentadoria e saúde mental: uma revisão de literatura. Cad. psicol. soc. trab., São Paulo, v. 16, n. 2, p. 199-209, dez. 2013. Disponível em <http://pepsic.bvsalud.org/scielo.php?script=sci_arttext\&pid=S1516$37172013000200005 \& \operatorname{lng}=$ pt\&nrm=iso>. Acesso em: 20 maio 2020. 
PAZZIM, Tanise Amália; PUGA, Debora Staub Cano Suarez de. (Org.). Preparação para aposentadoria: Conceitos e práticas. Curitiba: CRV, 2016. 438p.

SCHWEITZER, Lucas et al. Bases epistemológicas sobre sentido(s) e significado(s) do trabalho em estudos nacionais. Revista Psicologia: Organizações e Trabalho, v. 16, n. 1, mar. 2016. Disponível em: < http://pepsic.bvsalud.org/pdf/rpot/v16n1/v16n1a09.pdf $>$ Acesso em: 23 ago. 2020.

SILVA Anne Cristine Cavalcante; HELAL, Diogo Henrique. Programa de Preparação para Aposentadoria em uma Empresa Pública de Pernambuco: da análise à proposta de implementação. Teoria e Prática em Administração, v. 9, n. 2, 2019. Disponível em: $<$ https://periodicos.ufpb.br/ojs2/index.php/tpa/article/view/45515/27663 > Acesso em: 14 nov. 2020.

TOLFO, Suzana da Rosa; PICCININI, Valmíria. Sentidos e significados do trabalho: explorando conceitos, variáveis e estudos empíricos brasileiros. Psicologia e Sociedade, Porto Alegre, v. 19, n. 1, 2007. Disponível em: <

https://www.scielo.br/pdf/psoc/v19nspe/v19nspea07.pdf > Acesso: 03 ago. 2020. 